\title{
Histological, Immunohistochemical and Biochemical Study on the Possible Cardioprotective and Antihypertensive Role of the Flavonoid in Unilateral Renal Artery Ligation of Adult Albino Rats
}

\author{
Eman Mohamed Faruk ${ }^{1 *}$, Naser A. ElSawy ${ }^{2}$ and Rania Ebrahim El desoky ${ }^{1}$
}

${ }^{1}$ Department Histology and Cell Biology, Faculty of Medicine, Benha University, Egypt

${ }^{2}$ Department of Anatomy and Embryology Faculty of Medicine, Zagazig University, Egyp

\begin{abstract}
The blood pressure lowering effect of herbal-rich diet is a necessary dietary lifestyle measure now included the guidelines for the management of arterial hypertension. Flavonoids represent a major class of plant polyphenolics, they have antioxidant effects and show a wide range of pharmacological activities. This study was to clarify the antihypertensive effect of the flavonoid extracted from the Origanum vulgare.
\end{abstract}

Forty five adult male albino rats were classified into three main groups as follows: group I: control. Group II: hypertension was induced by ligation of left renal artery. Group III: hypertension was induced and given OV as 100 $\mathrm{mg} / \mathrm{kg}$ body weight daily for eight weeks. Blood samples were collected and cardiac sections were stained with H\&E and immunohistochemical staining for caspase 3 and Bcl-2.

The body weight of control, hypertensive and treated hypertensive groups showed a significant weight gain. Significant increase in creatinine and cholesterol in untreated in contrast to other groups. There was significant reduction of blood pressure (BP) on using OV in contrast to other groups. The hypertension group induced myocardial abnormalities as disruption, vacuolation, inflammation and wide separation of cardiac muscle fibers. Myocyte apoptosis were significantly decreased with OV compared with other groups. Caspases 3 and Bcl2 immunostaining in OV-treated rats were significantly decreased compared with other groups.

The supplementation of OV herbetic extract (flavonoid) in hypertensive rats partially prevented such occurred changes, suggesting its possible protective effect against the risk of the progression of cardiovascular diseases during hypertension.

Keywords: Hypertension; Cardiac muscle; Flavonoids; Bcl-2; Activated caspases 3

\section{Introduction}

Renal artery stenosis is associated with an increased incidence of cardiac death, myocardial infarction and stroke. In the Cardiovascular Health Study the presence of renovascular disease increased the risk of short-term adverse cardiovascular outcomes by approximately 2 -fold [1].

High blood pressure is one of the major risk factors for developing cardiovascular diseases, including coronary disease, stroke, peripheral artery disease; renal disease and heart failure [2]. Efforts to reduce the prevalence of hypertension have focused on non-pharmacologic approaches that lower blood pressure. The lifestyle measures that are widely agreed to lower blood pressure or cardiovascular risk associated with hypertension include smoking cessation, weight reduction, physical exercise, reduction of excessive alcohol intake and dietary measures such as a reduction in sodium, an increase in potassium and a decrease in saturated and total fat intake [3]. An increase in fruit and vegetable intake has also been included in the guidelines for the management of arterial hypertension in recent years [3]. Earlier epidemiological studies suggested that vegetarians tend to have lower blood pressures than non-vegetarians. The blood pressure lowering effects of vegetables and a fruit-rich diet were later confirmed in randomized intervention studies [4,5]. Because high blood pressure is the major cause of stroke, the blood pressure lowering effect could be one of the major mechanisms contributing to a reduced risk of stroke with increased fruit and vegetable intake [6]. The specific components present in fruits and vegetables that reduce blood pressure are not fully characterized. It was originally suggested that an increase in the ratio of polyunsaturated to saturated fats, fiber, calcium and magnesium intake, and a decrease in the intake of protein and vitamin B12 might be responsible. However, the reduction in blood pressure produced by these substances in trials of dietary supplements has typically been small and inconsistent. The presence of multiple antioxidants in these foodstuffs has also been suggested to be involved [7]. Among these plant antioxidants, polyphenolics have received considerable attention in recent years as compounds with potential beneficial effects for cardiovascular health. Flavonoids represent the major class of polyphenolics, which, in addition to their antioxidant effects, show a wide range of pharmacological activities [8]. The term flavonoid describes several thousand plant-derived compounds sharing a common skeleton of phenylchromane [7]. Origanum vulgare extract is a complex mixture extracted from leaves which contain different phytochemical groups such as alkaloids, saponins, coumarins, sterols, terpenes, tannins, Anthraquinone derivatives, Volatile oil and

*Corresponding author: Eman Mohamed Faruk, Department Histology and Cell Biology, Faculty of Medicine, Benha University, Egypt, Tel: 0020133221937; E-mail: faruk_eman@yahoo.com

Received April 01, 2015; Accepted April 28, 2015; Published April 30, 2015.

Citation: Faruk EM, EISawy NA, El desoky RE (2015) Histological, Immunohistochemical and Biochemical Study on the Possible Cardioprotective and Antihypertensive Role of the Flavonoid in Unilateral Renal Artery Ligation of Adult Albino Rats. J Cytol Histol 6: 326. doi:10.4172/2157-7099.1000326

Copyright: @ 2015 Faruk EM, et al. This is an open-access article distributed under the terms of the Creative Commons Attribution License, which permits unrestricted use, distribution, and reproduction in any medium, provided the original author and source are credited. 
Citation: Faruk EM, ElSawy NA, El desoky RE (2015) Histological, Immunohistochemical and Biochemical Study on the Possible Cardioprotective and Antihypertensive Role of the Flavonoid in Unilateral Renal Artery Ligation of Adult Albino Rats. J Cytol Histol 6: 326. doi:10.4172/21577099.1000326

flavonoids $[9,10]$. Also have different pharmacological activities not only as preventive but also as a treatment of some diseases with full relief of their symptoms [11]. The current research studies introduced many antihypertensive agents with limited adverse side effects, however the recognition of herbal remedies as another therapeutic alternatives (anti-thrombin activities) have been considered as an important goal for the pharmaceutical industries through their components [12]. Origanum vulgare displayed anti-platelet properties in human, has a role in controlling blood sugar and also inhibits abnormal cell growth, it also helps in maintaining healthy cholesterol and blood pressure [13] and is widely distributed through different regions as Morocco, Russa and Egypt [14].

The main pharmacological effects of Origanum vulgare are being anti-oxidant, anti-thrombin and potent anti-hypertensive through maintaining renal function, creatinine clearance and inhibiting mechanical forces acting on arterial wall so preventing excess hardening and thickening $[12,15]$.

The aim of this work was to study the effect of flavonoid on cardiac muscle of induced hypertensive rats through histological, immunohistochemical and biochemical examination.

\section{Material and Methods}

\section{Materials}

Plant extraction: Origanum vulgare obtained from Secum Pharmaceutical Company (24 Mohamed Hassan El Gamal St. 6th Zone, Nasr City, Cairo, Egypt).

The aerial part (leaves) of the plant material $(500 \mathrm{~g})$ was cleaned of foreign material, grinding and kept soaked for three days in the aqueousethanol (30:70) with occasional shaking, at room temperature then cover it by aluminum foiled paper and put it in dark place. The filtration was carried out using a muslin cloth and then through Whatman qualitative grade 1 filter paper. This procedure was repeated twice and then all the filtrates obtained were combined and concentrated on a rotary evaporator (RE-111, Buchi, Flawil, Switzerland) accompanied with B-700 recirculation chiller and a water bath model 461 at $45^{\circ} \mathrm{C}$ under vacum. Finally, the extract change to a thick pasty mass called as ethanol crude extract (Ov.Cr, $65 \mathrm{~g}$ ), yielding approximately 13\%The concentrated ethanolic extract was then suspended in distilled water $(300 \mathrm{ml})$ and filtered. The water soluble portion was defatted with $\mathrm{n}$-hexane $(3 \times 500 \mathrm{ml})$, the combined $\mathrm{n}$-hexane extract was concentrated under vacuo at 30 Centigrade $\left(30^{\circ} \mathrm{C}\right)$ to dryness $(27 \mathrm{~g})$. The defatted crude extract was partitioned several times with ethyl acetate $(3 \times 500$ $\mathrm{ml}$ ). The combined ethyl acetate extract was concentrated under vacuo at $40^{\circ} \mathrm{C}$ to dryness $(18 \mathrm{~g})$. The remaining aqueous extract subjected to freeze drying to afford a residue $(20 \mathrm{~g})$.

Then $1 \mathrm{~g}$ of each extract (Ethanolic extracts, Ethyl acetate extracts, and $\mathrm{n}$-hexane extracts) was dissolved or suspended in $250 \mathrm{ml}$ distilled water separately to give different extracts of concentration of $4 \mathrm{mg} / \mathrm{ml}$ $(100 \mathrm{mg} / \mathrm{kg}$ body weight) $[9,10]$

Animals: Forty five adult male albino rats were used in this study which has been carried out in the animal house of the Faculty of Medicine, Zagazig University. They were housed in a temperaturecontrolled and light controlled room (12 h light/dark cycle), with free access to food and water. They were housed in three groups in plastic cages. Rats were fed ad libitum. The rats were randomly collected and divided into 3 groups ( 15 animals each), the first group was considered as a control, the second as hypertensive untreated while the third group as hypertensive treated with Origanum vulgare.

\section{Methods}

Measurement of blood pressure and biochemical studies: All 45 animals were weighed before starting the study and initial blood samples were collected from the vein of the neck for creatinine.

The first group followed up through the period of study by measuring the systolic blood pressure and biochemistry every 2 weeks for 8 weeks (period of study).

In the second group, The animals were anesthetized with intraperitoneal injection of thiopental sodium (Thiopental; Eipico) at a dose of $80 \mathrm{mg} / \mathrm{kg}$ body weight then hypertension was induced by ligation of left renal artery to raise systolic BP to more than $150 \mathrm{mmHg}$ and they were randomly assigned on a daily placebo (water) during the 8 weeks, starting from the raised systolic BP point, via a stomach tube. Systolic blood pressure was measured every 2 weeks till the end of study by a tail cuff plethysmographic noninvasive methods (Letica LE 5100, panlab, Barcelona, Spain).

The third group in which hypertension was induced as mentioned above and systolic pressure was above $150 \mathrm{mmHg}$ were treated with Origanum vulgare given orally by gastric intubation for 8 weeks.

After 8 weeks of starting the study, the aorta was exposed, cannulated with polyethylene catheter and connected to a blood pressure monitor transducer $8 / 38$ to monitor the mean arterial pressure and then blood samples were collected from the aortic cannula in heparinized tubes for final analytical assays for creatinine. The rats were finally weighed and killed with an overdose of phenobarbital.

Light microscopic studies: The heart specimens obtained were fixed in $10 \%$ formol saline, processed, and embedded in paraffin sections. Sections were cut into $5 \mu \mathrm{m}$ thicknesses using a microtome, mounted on slides, and subjected to the following techniques: H\&E stain for histological assessment [16].

Immunohistochemical study: Immunostaining was performed using the avidin biotin peroxidase technique for localization of activated caspases 3 and Bcl-2. Paraffin sections mounted on coated slides were deparaffinized and treated with $0.01 \mathrm{~m}$ citrate buffer for 10 minutes to unmask antigens21. Then sections were incubated in $\mathrm{H}_{2} \mathrm{O}_{2}$ for 10 minutes to abolish endogenous peroxidase activity before blocking with $5 \%$ serum for $2 \mathrm{~h}$ at room temperature to inhibit nonspecific immunoreaction with a monoclonal rat anti-caspase-3 antibody (Lab vision, USA). Immunohistochemical staining for $\mathrm{Bcl}-2$ was carried out according to the manufacturer's protocol. Paraffin-embedded tissue sections, 3-4 $\mu \mathrm{m}$ thick, were mounted on positively charged slides and heated at $60^{\circ} \mathrm{C}$ for $30 \mathrm{~min}$. They were then deparaffinized and rehydrated through a series of xylene and alcohol before staining. Antigen retrieval was carried out with microwave treatment in $10 \mathrm{mmol} / \mathrm{l}$ citrate buffer (Neo-Markers; Thermo Fisher Scientific Inc., Rockford, Illinois, USA).

Slides were then incubated overnight at $4^{\circ} \mathrm{C}$ with polyclonal rabbit anti-Bax (dilution 1:50; Dako Cytomation Norden A/S, Glostrup, Denmark,which it is the blocking solution). Excess antiserum was rinsed from the slide by immersing in cold buffer for 2 changes of 5 to 10 minutes each. Then the slide were incubated with secondary antibody (dilution 1:1000) for 1 hour and then washed by buffer and substrate was added. DAB substrate chromogen solution was applied and incubated for 10-15 min until color intensity was reached. Sections were counterstained with hematoxylin. Sections treated with the same protocol in the absence of the primary antibodies served as negative controls [17]. 
Citation: Faruk EM, ElSawy NA, El desoky RE (2015) Histological, Immunohistochemical and Biochemical Study on the Possible Cardioprotective and Antihypertensive Role of the Flavonoid in Unilateral Renal Artery Ligation of Adult Albino Rats. J Cytol Histol 6: 326. doi:10.4172/21577099.1000326

Morphometric analysis: In each group, five different casapase-3 and $\mathrm{Bcl}-2$ stained sections were examined $(\mathrm{n}=5)$. Five high-power fields (400X) were measured per section and their mean was achieved. Measurements were taken using a Leica Q win software program installed on a PC (Dell, Round Rock, Texas, USA) connected to a microscope (Leica Microsystem, Heerbrugg, Switzerland). Data were presented as mean \pm SEM.

The following measurements were taken:

1. Mean area $\%$ of caspases 3 immunoreactivity.

2. Mean area $\%$ of Bcl-2 immunoreactivity.

\section{Statistical Analysis}

The findings in this study were recorded as mean, standard error of mean (SEM).Student's $t$ test was used and both $t$ and probability $(\mathrm{p})$ values were estimated. The results were considered significant when the two tailed $p$ value was less than $0.05[18,19]$.

\section{Results}

\section{Body weight}

The recorded results of the body weight of control animals ranged from 195 to $218 \mathrm{gm}$ with a mean of $207.4 \pm 2.2$ while the final body weight ranged 213 to $240 \mathrm{gm}$ with a mean of $223.5 \pm 2.6 \mathrm{gm}$. In untreated hypertensive rats, the initial body weights ranged 199-232 gm with a mean of $214.5 \pm 3.2 \mathrm{gm}$ while the final body weight ranged $180-215 \mathrm{gm}$ with a mean of $197.6 \pm 4.2 \mathrm{gm}$.

In treated hypertensive group, the initial body weights ranged 200$225 \mathrm{gm}$ with a mean of $192.7 \pm 2.4 \mathrm{gm}$ while the final body weights ranged 218-243 gm with a mean of $229.5 \pm 2.6 \mathrm{gm}$. A highly significant increase in body weight $(\mathrm{P}<0.02)$ was noticed in all groups (Table 1$)$.

\section{Blood pressure and biochemical results}

Blood pressure estimation: In control group the initial systolic BP

\begin{tabular}{|l|c|c|c|}
\hline & Control rats & Untreated hypertension & Treated hypertensive \\
\hline Mean \pm SD & $223.5 \pm 2.6$ & $197.6 \pm 4.2$ & $229.5 \pm 2.6$ \\
\hline
\end{tabular}

A significant increase in body weight $(\mathrm{P}<0.02)$ was noticed in treated group.

Table 1: Means \pm SD of Body weight of control, untreated hypertensive and treated hypertensive rats.

\begin{tabular}{|c|c|c|c|c|c|}
\hline & \multirow{2}{*}{$\begin{array}{l}\text { Initial } \\
\text { systolic BP }\end{array}$} & \multicolumn{3}{|c|}{ Follow up systolic BP } & \multirow{2}{*}{$\begin{array}{l}\text { Final } \\
\text { systolic BP }\end{array}$} \\
\hline & & $2 W$ & $4 W$ & $6 \mathrm{~W}$ & \\
\hline Control & $130 \pm 5$ & $138 \pm 7$ & $128 \pm 5$ & $142 \pm 6$ & $136 \pm 6$ \\
\hline Untreated hypertension & $163 \pm 6$ & $168 \pm 5$ & $182 \pm 8$ & $178 \pm 7$ & $186 \pm 8$ \\
\hline Treated hypertension & $166 \pm 6$ & $158 \pm 5$ & $146 \pm 6$ & $148 \pm 7$ & $138 \pm 4$ \\
\hline
\end{tabular}

A significant increase in $B P$ in untreated group $(P=0.02)$ and a significant reduction in $\mathrm{BP}$ in treated group $(\mathrm{P}<0.05)$.

Table 2: Means \pm SD of initial, during follow up and final measurements of systolic blood pressure $(\mathrm{mmHg})$ in all groups of rats.

\begin{tabular}{|l|l|l|l|}
\hline Mean \pm SD & Control rats & Hypertensive & Treated hypertensive \\
\hline Serum creatinine (mgldl) & $0.9 \pm 0.1$ & $2.08 \pm 0.12$ & $0.9 \pm 0.07$ \\
\hline
\end{tabular}

A highly significant increase in creatinine levels $(p<0.02)$ was found in untreated hypertensive group in contrast to treated and control groups.

Table 3: Means \pm SD of serum creatinine $(\mathrm{mg} / \mathrm{dl})$ in control, untreated hypertensive and treated hypertensive rats. ranged $113-145 \mathrm{mmHg}$ with a mean of $130+5 \mathrm{mmHg}$ and final values ranged $128-144 \mathrm{mmHg}$ with a mean of $136 \pm 6 \mathrm{mmHg}$.

In untreated hypertensive rats the initial systolic BP ranged 155$178 \mathrm{mmHg}$ with a mean of $163 \pm 6 \mathrm{mmHg}$ while the final values ranged $168-194 \mathrm{mmHg}$ with a mean of $186 \pm 8 \mathrm{mmHg}$. In treated group the initial systolic BP ranged $156-171 \mathrm{mmHg}$ with a mean of $166 \pm 6$ $\mathrm{mmHg}$ and the final values after 8 weeks ranged $125-156 \mathrm{~mm} / \mathrm{Hg}$ with a mean of $138 \pm 4 \mathrm{mmHg}$. There was a significant increase in BP in untreated group $(\mathrm{P}=0.02)$ and a significant reduction in $\mathrm{BP}$ in treated group $(\mathrm{P}<0.05)$ (Table 2$)$.

Serum creatinine: The initial creatinine levels in control rats ranged from $0.4-1.2 \mathrm{mg} / \mathrm{dl}$ with a mean of $1 \pm 0.15 \mathrm{mg} / \mathrm{dl}$ and final levels after 8 weeks ranged $0.5-1.2 \mathrm{mg} / \mathrm{dl}$ with a mean of $0.9 \pm 0.1 \mathrm{mg} /$ dl. In untreated hypertensive group, the initial creatinine values ranged $0.4-1.4 \mathrm{mg} / \mathrm{dl}$ with a mean of $0.9 \pm 0.09 \mathrm{mg} / \mathrm{dl}$ while the final values after 8 weeks ranged $1.6-2.6 \mathrm{mg} / \mathrm{dl}$ with a mean of $2.08 \pm 0.12 \mathrm{mg} /$ $\mathrm{dl}$ while in treated group, the initial values ranged $0.5-1.1 \mathrm{mg} / \mathrm{dl}$ with a mean of $0.8 \pm 0.06 \mathrm{mg} / \mathrm{dl}$ while the final values ranged $0.5-1.3 \mathrm{mg} /$ $\mathrm{dl}$ with a mean of $0.9 \pm 0.07 \mathrm{mg} / \mathrm{dl}$. A highly significant increase in creatinine levels $(\mathrm{p}<0.02)$ was found in untreated hypertensive group in contrast to treated and control groups (Table 3).

\section{Histological results}

H\&E stain: Light microscopic examination of cardiac muscle of the control group showed a normal myofibrillar structure with striations, branched appearance and continuity with adjacent myofibrils. Myocytes exhibited an acidophilic sarcoplasm and central oval single nuclei (Figure 1). Longitudinally arranged fibers were cylindrical with

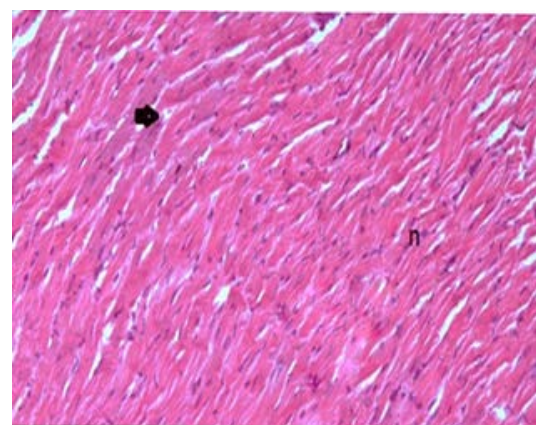

Figure 1: A photomicrograph of a section in the cardiac muscle from the control group showing branching and anastomosing cardiac myocytes with central oval nuclei (arrows) and acidophilic sarcoplasm (H\&E 200X).

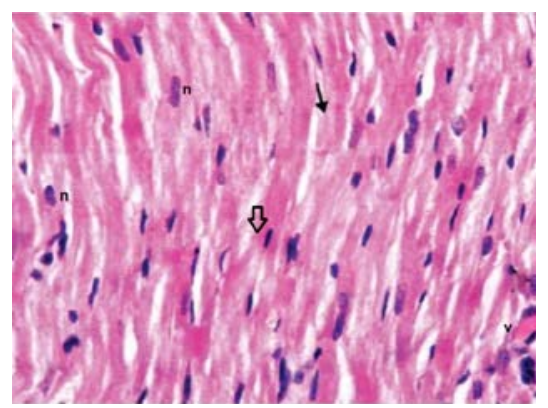

Figure 2: A Higher magnification of a section in the cardiac muscle of a control rat (group I) showing cylindrical branching of cardiac myocytes with an acidophilic sarcoplasm (black arrow) and single oval central vesicular nuclei ( white arrow). Capillaries are found in the Connective Tissue between cardiac myocytes (v) (H\&E 400X). 
Citation: Faruk EM, ElSawy NA, El desoky RE (2015) Histological, Immunohistochemical and Biochemical Study on the Possible Cardioprotective and Antihypertensive Role of the Flavonoid in Unilateral Renal Artery Ligation of Adult Albino Rats. J Cytol Histol 6: 326. doi:10.4172/21577099.1000326

Page 4 of 8

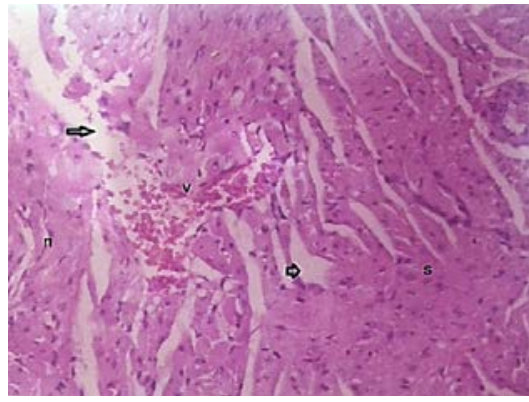

Figure 3: A photomicrograph of a section in the cardiac muscle from the Hypertensive group (group II) showing wavy fibers separated by wide endomysium with focal disruption of some fibers(arrows), dark acidophilic sarcoplasm (s), peripheral dark nuclei ( $\mathrm{n}$ ) in some fibers, with extravasation of blood between muscle fibers (v) (H\&E 200X).

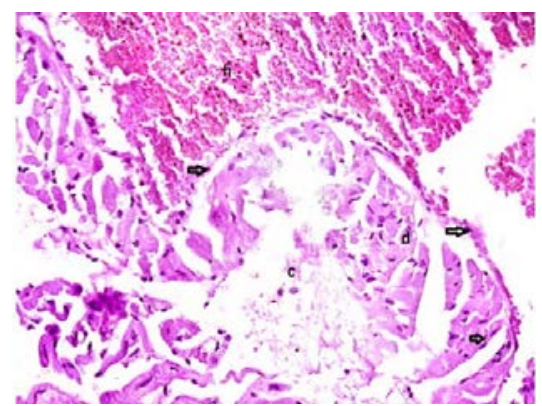

Figure 4: A photomicrograph of a section in the cardiac muscle from group II showing wide separated cardiac myocytes, most of which appear degenerated (c), edema with pale acidophilic sarcoplasm and peripheral small dark nuclei (arrows). Notice presence of focal haemorrhage (H\&E 200X).

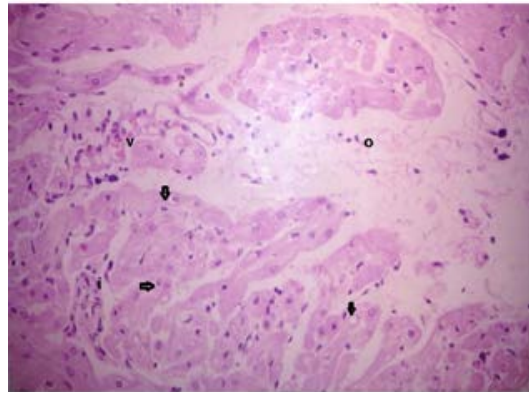

Figure 5: A photomicrograph of a section in the cardiac muscle from group I showing extensive degeneration of myofibrils with edema and vacuolization ( arrows) and presence of extravasation of blood between muscle fibers (v). Notice presence of mononuclearcellular infiltration (i) (H\&E 200X).

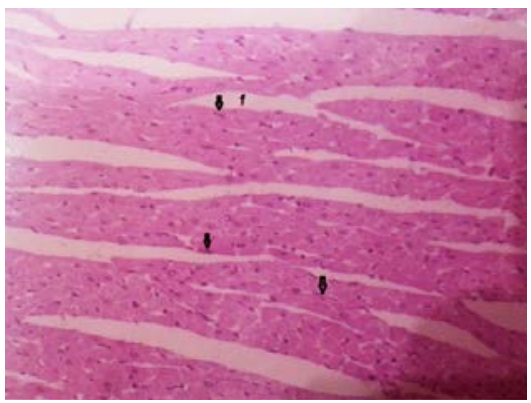

Figure 6: A photomicrograph of a section in the cardiac muscle from treated group (group III) showing well maintained separated of muscle fibers (f) and peripheral dark nuclei in some fibers nuclei (arrows) (H\&E 200X). central oval vesicular nuclei and faint striations. Cardiac myocytes were connected to make fibers through intercalated discs (Figure 2). The interfiber spaces were narrow and contained blood vessels and fibroblasts (Figures 1 and 2).

The cardiac muscle fibers of group II (hypertensive group) showed separation of myofibers with increase in the interfiber spaces and extravasated RBCs (Figure 3). In addition, large areas of hemorrhage could also be detected [4]. Focal degeneration was evident in this group, degenerated cardiac myocytes appeared swollen. They were either pale with vacuolated cytoplasm (especially around the nucleus) or darkly stained nuclei (Figures 4 and 5). Focal mononuclear cellular accumulation could also be detected in many areas (Figure 5).

Treated group, showed a histological pattern nearly similar to the control group. Most of the cardiac muscle fibers appeared cylindrical, with central oval nuclei. However, many wide interfiber spaces were still detected (Figure 6). Nevertheless, some areas showed pale vacuolated cardiac muscle fibers and others revealed extravasated blood in the wide interfiber spaces (Figure 7).

\section{Immunohistochemical results}

Bcl2 expression: Positive immunohistochemical staining of bcl2 demonstrated brown cytoplasmic staining (index for the antiapoptotic effect). Cardiac sections stained with anti-Bcl2 antibodies showed a strong positive immunostaining for $\mathrm{Bcl} 2$ in the cytoplasm of most cardiac cells of the control group (group I) (Figure 8). In the hypertensive group (group II), few cardiac cells showed moderate immunoreactivity for Bcl2 (Figure 9) treatment with OV (group III) resulted in a marked

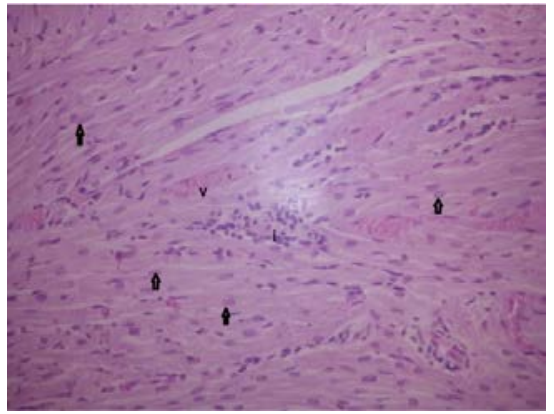

Figure 7: A Higher magnification of a section in the cardiac muscle from treated group (group III) showing most of cardiac myocytes appearing normal with central oval nuclei (arrows) and presence of extravasation of blood between muscle fibers (v). Notice presence of mononuclearcellular infiltration (i) (H\&E 200X).

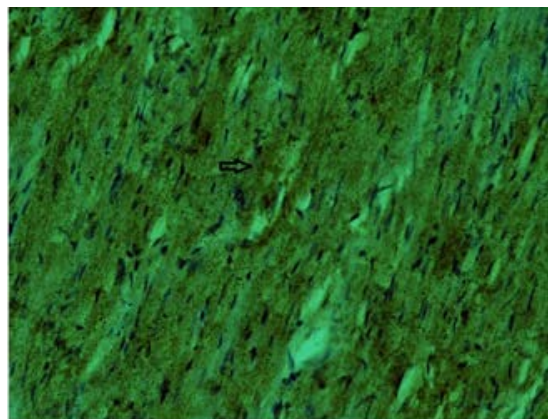

Figure 8: A photomicrograph of a section in the cardiac muscle of a control rat (group I) showing strong positive immunoreactivity for $\mathrm{Bcl} 2$ in the cytoplasm of myocardial cells (arrow) (Bcl2 immunostain 400X). 
Citation: Faruk EM, ElSawy NA, El desoky RE (2015) Histological, Immunohistochemical and Biochemical Study on the Possible Cardioprotective and Antihypertensive Role of the Flavonoid in Unilateral Renal Artery Ligation of Adult Albino Rats. J Cytol Histol 6: 326. doi:10.4172/21577099.1000326

Page 5 of 8

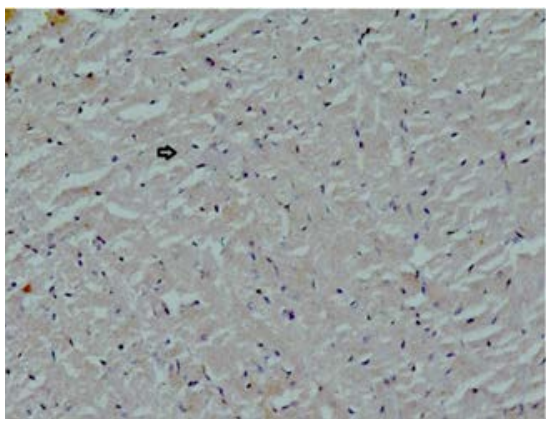

Figure 9: A photomicrograph of a section in the cardiac muscle of a rat (group II) showing a marked reduction in the immunostaining for Bcl2. A few myocardial cells show moderate immunostaining for $\mathrm{Bcl} 2$ in their cytoplasm (arrow) (Bcl2 immunostain 400X)

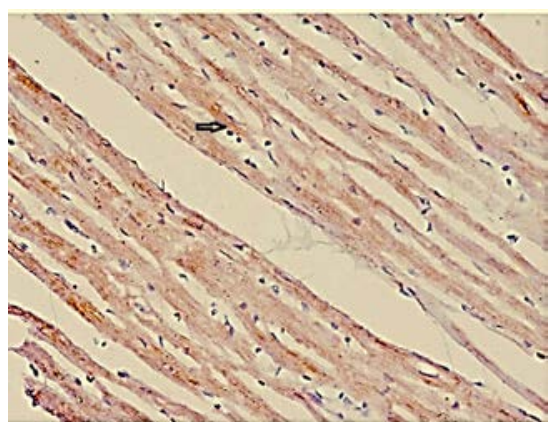

Figure 10: A photomicrograph of a section in the cardiac muscle of a rat (group III) showing weak immunoreactivity for $\mathrm{Bcl} 2$ in the cytoplasm of myocardial cells (arrow) (Bcl2 immunostain 400X).

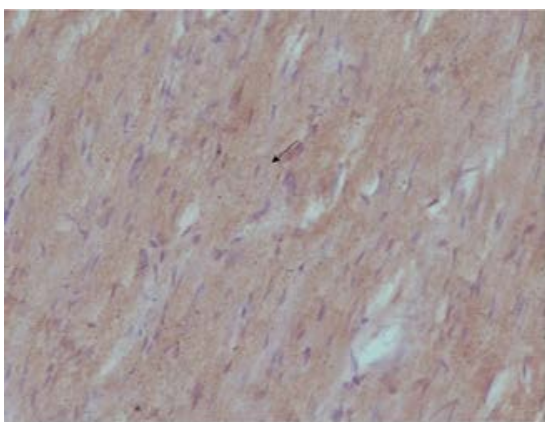

Figure 11: A photomicrograph of a section in the cardiac muscle of a contro rat (group I) showing week immunoreactivity for caspase in the cytoplasm of myocardial cells (arrows) and in their cell membranes (curved arrows). (Caspase 3 immunostain 400X).

increase in Bcl2 immunoreactivity as many cardiac cells showed a positive reaction for Bcl2 (Figure 10).

Caspase-3 expression: Positive immunohisto-chemical staining of caspase- 3 demonstrated as brown cytoplasmic staining (index for the degree of nuclear apoptosis). Cardiac sections stained with anticaspase 3 antibodies showed weak immunostaining in the cytoplasm in the control group (Figure 11). Hypertensive group (group II) showed marked increase in caspase 3 expression in the cytoplasm of many cardiac cells that showed a strong reaction (Figure 12). In the OVtreated group (group III), the expression of caspase 3 by cardiac cells was markedly reduced as compared with (group II) (Figure 13).

\section{Morphometric and statistical results}

Mean area\% of $\mathrm{Bcl} 2$ immunoreactivity: There was a significant decrease in the mean area\% of $\mathrm{Bcl} 2$ immunoreactivity in group II $(1.73 \pm 1.30)$ when compared with the control group $(5.10 \pm 2.56)$, with a $P$ value $(0.006)$. In group III, the mean area\% of Bcl2 (6.32 \pm $1.35)$ was significantly increased as compared with that of group II $(P$ value 0.001$)$. No significant difference was found between group III and control group I ( $P$ value 2.001) (Table 1).

Mean area\% of caspase 3 immunoreactivity: There was a significant increase in mean area\% of caspase 3 immunoreactivity in group II $(12.32 \pm 1.93)$ compared with the control group (5. $10 \pm 2.12)$, with a $P$ value (0.001). In group III, the mean area\% of caspase $3(7.12$ \pm 1.81 ) was significantly decreased as compared with group II ( $P$ value $0.039)$, but still significantly increased as compared with the control group ( $P$ value 0.021$)$ (Table 4$)$.

\section{Discussion}

Hypertension is a risk factor for many cardiovascular diseases. Control of hypertension by dietary anti-hypertensive agents is an important strategy to manage this risk factor. Here, we have analyzed the effects of the dietary flavonoid Origanum vulgare on cardiac muscle in a model of hypertension. A significant weight gain was recorded in our study in all groups of experimental animals which didn't agree with aguila [20] who didn't record any changes in body weight of experimental induced hypertensive animals on long-term intake of edible oils.

In the present work unilateral renal artery ligation was performed to induce hypertension. Deteriorated renal function was confirmed in the present work by the presence of statistically significant increase in

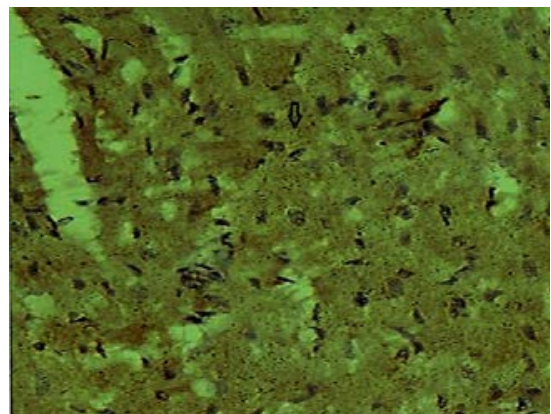

Figure 12: A photomicrograph of a section in the cardiac muscle of a rat (group II) showing strong positive immunoreactivity for caspase 3 in the cytoplasm of myocardial cells ( arrows ) (Caspase 3 immunostain 400X).

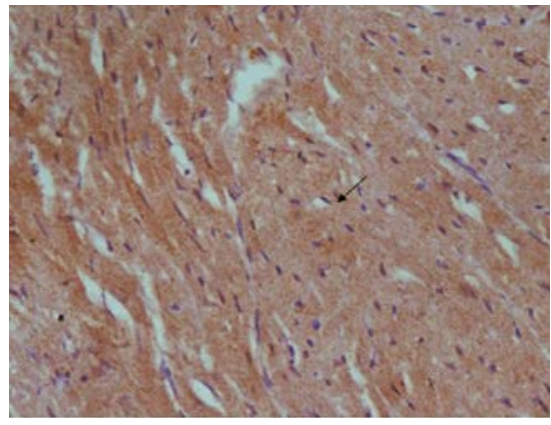

Figure 13: A photomicrograph of a section in the cardiac muscle of a rat (group III) showing weak immunoreactivity for caspase 3 (arrows) in the cytoplasm of myocardial cells. (Caspase 3 immunostain 400X). 
Citation: Faruk EM, EISawy NA, El desoky RE (2015) Histological, Immunohistochemical and Biochemical Study on the Possible Cardioprotective and Antihypertensive Role of the Flavonoid in Unilateral Renal Artery Ligation of Adult Albino Rats. J Cytol Histol 6: 326. doi:10.4172/21577099.1000326

\begin{tabular}{|l|l|l|l|l|}
\hline Group & Mean area\% ofBcl2 & P value & $\begin{array}{l}\text { Mean area\% } \\
\text { of caspases 3 }\end{array}$ & P value \\
\hline Group I & $5.10 \pm 2.56$ & $\begin{array}{l}0.006^{*} \text { vs. II } \\
2.43 \text { vs. III }\end{array}$ & $5.10 \pm 2.12$ & $\begin{array}{l}0.001^{*} \text { vs. II } \\
0.021^{*} \text { vs. III }\end{array}$ \\
\hline Group II & $1.73 \pm 1.30$ & $\begin{array}{l}0.006^{*} \text { vs.I } \\
0.001^{*} \text { vs. III }\end{array}$ & $12.32 \pm 1.93$ & $\begin{array}{l}0.001^{*} \text { vs. I } \\
0.39 \text { vs. III }\end{array}$ \\
\hline Group III & $6.32 \pm 1.35$ & $\begin{array}{l}0.288 \text { vs. I } \\
0.001^{*} \text { vs. II }\end{array}$ & $7.12 \pm 1.81$ & $\begin{array}{l}0.021^{*} \text { vs. I } \\
0.039 \text { vs. II }\end{array}$ \\
\hline
\end{tabular}

*The mean difference is significant at a $P$ value $\leq 0.05$

Table 4: Mean area \% of Bcl2 and caspase 3 immunoreactivity in cardiac myocytes of the all groups.

serum creatinine level which was due most likely to a drop of number of functioning nephrons agreed with Cullen-Mcewen [21] who reported that different aspects should be considered concerning loss of glomeruli in hypertension and estimation of glomeruli number and glomerular volume which all allowed to inform about the renal response to hypertension progression and/or antihypertensive treatment efficiency. Other study reported that the common renal injury of diabetes and hypertension is a complex dynamic process involving several players such as inflammatory agent, cytokines, vasoactive agents and enzymes participating in extracellular matrix assembly, anchoring or degradation [22]. The histological results of the current work revealed degeneration and inflammatory cell infiltration of the cardiac myocytes in the hypertensive group which is agreed with [23]. The pathophysiological mechanism underlying renal hypertension involves activation of the renin-angiotensin-aldosterone system. Left renal artery (LRA) ligation produces renal ischemia initiating hypersecretion of renin and subsequent activation of renin-angiotensin-aldosterone system. Angiotensin-II-mediated vasoconstriction and aldosterone-induced sodium and water retention cause a rise in BP. The main actions of angiotensin-II include generalized vasoconstriction, increased release of noradrenaline from sympathetic nerve terminals, stimulation of proximal tubular reabsorption of sodium and alteration in cardiovascular structures [24]. These lesions might be due to increased heart strain, although the perivascular accentuation might indicate a toxicological effect [25]. Accumulation of various toxins appeared to be due to the reduced glomerular filtration rate and diminished tubular excretion [26]. The present study supported the idea of beneficial effect of OV intake supplementation to hypertensive rats. Administration of Origanum vulgare, resulted in a remarkable reduction in systolic which might be due to the antioxidant ability of this compound. Flavonoids and triterpine were recently shown to reduce hypertension in experimental animal models [27]. Several cohort studies have suggested that high intake of flavonoids may decrease the risk of coronary heart diseases [28]. In this work control of blood pressure by OV in treated hypertensive group has markedly delayed and slightly improved the histological changes that appeared in untreated hypertensive rats which coincided with Eddouks [29] who have demonstrated the importance of intensive BP control preferably systolic BP less than $130 \mathrm{mmHg}$ to delay progression of renal disease in hypertension and diabetes. The significant drop of systolic BP in treated hypertensive rats with $\mathrm{OV}$ as shown in this study agreed and fully explained by Engler [30] and Aguila [31] who reported that OV reduced the BP by reduction of vascular reactivity to noradrenaline blunting the rennin-angiotensinaldosterone system by decreasing adrenal synthesis of aldosterone.

Hypertension accelerated the aging process of both kidney and heart like hypertrophic changes which led to structural destruction [32] while in the present study OV has reduced and alleviated pathological damage in both kidney and aorta which coincided with Lermioglu [33] who related these effects due most likely to reduced toxins released in hypertensive rats treated by OV. Different antihypertensive medications are now available in the market with different biological effects in hypertensive human subject. However very little data are published about the histopathological abnormalities resulted from using of such extracts and also no enough references were reported to deal with histological effect of Origanum vulgare on heart of the experimental animals. Myocardial cell death via necrosis and apoptosis is the primary feature of ischemia and reperfusion due to hypertension. Reducing cardiocyte loss through suppression of cell death is a logical strategy to protect cardiomyocytes [34] Caspases, a family of cysteine proteases that cleave to aspartate residues, are central to the execution of apoptosis [35]. During the execution phase of apoptosis, initiator caspases activate effector caspases and ultimately cleave a set of proteins, disassembling the cell [36]. Some studies suggest that caspase-3 may be the main cause of cells apoptosis [34]. Apoptosis via activation of distinct signaling pathways involves mitochondria, mitochondrial regulatory proteins, and caspase activation [34,36]. Caspase activation may be regulated directly or indirectly by members of the Bcl-2 family of proteins. Bcl-2 proteins play a critical role in regulating apoptosis by promptly impacting caspase activation on multiple levels. The main site of action of anti-apoptotic Bcl-2 proteins appears to be the mitochondrion, which resides in the outer mitochondrial wall and regulates apoptosis by inhibiting the release of cytochrome $c$ [34]. Bax, one of the proapoptotic proteins, originates in the cytosol but translocates to the mitochondria and forms a pro-apoptotic complex with Bcl-2. In particular, the balance of Bcl-2 and Bax expression has been suggested as an important factor in determining the extent of apoptosis [35]. Therefore, in the present study, the expression of Bcl-2 family was examined immunohistochemically to elucidate the involvement of $\mathrm{Bcl}$ 2 in hypertension induced apoptosis .Examination of the cardiac muscle of the hypertensive rats that were stained immunohistochemically for caspase 3 revealed intense positive immunoreaction in the cardiac myocytes that statistically were confirmed by comparison with that observed in the control. In hypertensive rats, weak immunostaining for Bcl-2 was demonstrated in most of cardiac cells, this result was in accordance with that observed by other authors who suggest that hypertensin induced apoptosis was induced by a down regulation of Bcl-2 and this was concomitant with activation of caspase- 3 which mediates apoptosis $[37,38]$. On the other hand, it was documented that hypertensin induce apoptosis in cardiac musle via activation of Bax expression and Bcl-2 suppression [39]. Cardiomyocyte loss due to multiple mechanismsof death, including apoptosis [40]. Besides a reduction inthe number of cardiomyocytes, apoptosis may contribute to heart failure through different pathways [41]. Thus, apoptosis may be one of the mechanisms involved in the loss of contractile mass and function in hypertensive cardiomyopathy. It is well known that apoptosis is associated with activation of caspases that mediate the cleavage of vital and structural proteins. Communal et al. [42] have reported recently that caspase- 3 cleaved cardiac myofibrillar proteins, resulting in an impaired force/Ca relationship and myofibrillar ATPase activity. In this regard, Laugwitz et al. [43] have demonstrated that caspase activation is associated with cleavage of myofilaments oxidant stress is an important factor inducing cardiomyocyte apoptosis. Thus, antioxidant therapy, whether through administration of additional antioxidants or by boosting innate antioxidant mechanisms, has been shown to be a viable approach in reducing cardiac apoptosis in experimental conditions [44]. In this study, a concomitant administration of Origanum Vulgari in the hypertensive group significantly reduced the hypertensive -induced apoptotic changes in cardiac muscles of rats, but not completely recovering the histopathological changes to normal. Also, we observed diminished immunostaining for Bcl-2 protein when compared with 
Citation: Faruk EM, EISawy NA, El desoky RE (2015) Histological, Immunohistochemical and Biochemical Study on the Possible Cardioprotective and Antihypertensive Role of the Flavonoid in Unilateral Renal Artery Ligation of Adult Albino Rats. J Cytol Histol 6: 326. doi:10.4172/21577099.1000326

Page 7 of 8

those of treated group. Origanum Vulgari was reported to have antioxidant effect [45].

Spiridon et al they found that Origanum vulgare and Melissa officinalis extracts present the most effective antioxidant capacity in scavenging DPPH radicals.

They reported that oxidative stress plays a role in mediating apoptosis through mitochondrial dysfunction. This damage may change mitochondrial membrane permeability, which leads to the release of cytochrome c into the cytosol and commits the cell to apoptosis [46,47].

In conclusion, our results demonstrate that Origanum vulgare, possesses antihypertensive effect against hypertensive rats, which is evidenced by a considerable decrease in blood pressures, renal function. Our results also revealed that the cardiac damage was decreased by Origanum vulgare supplementation. Further studies are needed to find out the exact mechanism of action of Origanum vulgare.

\section{References}

1. Edwards MS, Hansen KJ, Craven TE, Bleyer AJ, Burke GL, et al. (2004) Associations between renovascular disease and prevalent cardiovascular disease in the elderly: a population-based study. Vasc Endovascular Surg 38: 25-35.

2. D'Agostino RB Sr, Vasan RS, Pencina MJ, Wolf PA, Cobain M, et al. (2008) General cardiovascular risk profile for use in primary care: the Framingham Heart Study. Circulation 117: 743-753.

3. Mancia G, De Backer G, Dominiczak A, Cifkova R, Fagard R, et al. (2007) ESH-ESC Task Force on the Management of Arterial Hypertension. $2007 \mathrm{ESH}$ ESC Practice Guidelines for the Management of Arterial Hypertension: ESHESC Task Force on the Management of Arterial Hypertension. J Hypertens 25 1751-1762.

4. Appel LJ, Moore TJ, Obarzanek E, Vollmer WM, Svetkey LP, et al. (1997) A clinical trial of the effects of dietary patterns on blood pressure. DASH Collaborative Research Group. N Engl J Med 336: 1117-1124

5. Margetts BM, Beilin LJ, Vandongen R, Armstrong BK (1986) Vegetarian diet in mild hypertension: a randomised controlled trial. Br Med J (Clin Res Ed) 293: 1468-1471.

6. He FJ, Nowson CA, MacGregor GA (2006) Fruit and vegetable consumption and stroke: meta-analysis of cohort studies. Lancet 367: 320-326.

7. Manach C, Scalbert A, Morand C, Rémésy C, Jiménez L (2004) Polyphenols: food sources and bioavailability. Am J Clin Nutr 79: 727-747.

8. Middleton E Jr, Kandaswami C, Theoharides TC (2000) The effects of plan flavonoids on mammalian cells: implications for inflammation, heart disease, and cancer. Pharmacol Rev 52: 673-751.

9. Lemhadri A, Zeggwagh NA, Maghrani M, Jouad H, Eddouks M (2004) Antihyperglycaemic activity of the aqueous extract of Origanum vulgare growing wild in Tafilalet region. J Ethnopharmacol 92: 251-256.

10. Srihari T, Sengottuvelan M, Nalini N (2008) Dose-dependent effect of oregano (Origanum vulgare L.) on lipid peroxidation and antioxidant status in 1,2-dimethylhydrazine-induced rat colon carcinogenesis. J Pharm Pharmacol 60: 787-794

11. Burt S2004) Essential oils: their antibacterial properties and potential applications in foods--a review. Int J Food Microbiol 94: 223-253.

12. Goun E, Cunningham G, Solodnikov S, Krasnykch O, Miles H (2002) Antithrombin activity of some constituents from Origanum vulgare. Fitoterapia 73: $692-694$

13. Elkayam A, Mirelman D, Peleg E, Wilchek M, Miron T, et al. (2003) The effects of allicin on weight in fructose-induced hyperinsulinemic, hyperlipidemic, hypertensive rats. Am J Hypertens 16: 1053-1056.

14. Chabarovs K (2007) Origanum Vulgare USDA NRCS The plants data base National Plant. Data centre Baton Rouge, LA, 70874-4490 USA.

15. Kulisic T, Radonic A, Katalinic V, Milos M (2004) Use of different methods for testing antioxidative activity of oregano essential oil. Food Chemistry 85: 633-640.

16. Bancroft JD, Layton C (2013) The Hematoxylin \& eosin and Carbohydrates.
In: Suvarna SK, Layton C, Bancroft JD (eds.) Theory \& Practice of histological techniques (7thedn.) Churchill Livingstone of EISevier, Philadelphia, pp. 173$186,215-238$.

17. Jackson P Blythe D (2013) Immunohistochemical techniques. In: Suvarna SK, Layton C, Bancroft JD (eds.) Theory \& Practice of histological techniques (7thedn.) Churchill Livingstone of EISevier, Philadelphia, USA.

18. Wilcox RR (2009) Basic statistics: understanding conventional methods and modern insights (1stedn.) Oxford, New York.

19. Aguila MB, Sa Silva SP, Pinheiro AR, Mandarim-de-Lacerda CA (2004) Effects of long-term intake of edible oils on hypertension and myocardial and aortic remodelling in spontaneously hypertensive rats. J Hypertens 22: 921-929.

20. Cullen-McEwen LA, Kett MM, Dowling J, Anderson WP, Bertram JF (2003) Nephron number, renal function, and arterial pressure in aged GDNF heterozygous mice. Hypertension 41: 335-340.

21. González-Albarrán O, Gómez O, Ruiz E, Vieitez P, García-Robles R (2003) Role of systolic blood pressureon the progression of kidney damage in an experimental model of type 2 diabetes mellitus, obesity, and hypertension (Zucker rats). Am J Hypertens 16: 979-985.

22. Xue JL, Frazier ET, Herzog CA, Collins AJ (2005) Association of heart disease with diabetes and hypertension in patients with ESRD. Am J Kidney Dis 45: 316-323.

23. Callera GE, Yeh E, Tostes RC, Caperuto LC, Carvalho CR, et al. (2004) Changes in the vascular beta-adrenoceptor-activated signalling pathway in 2Kidney-1Clip hypertensive rats. Br J Pharmacol 141: 1151-1158.

24. Rostand SG2000) Coronary heart disease in chronic renal insufficiency: some management considerations. J Am Soc Nephrol 11: 1948-1956.

25. Vaziri ND2009) Causes of dysregulation of lipid metabolism in chronic renal failure. Semin Dial 22: 644-651.

26. Jalili T, Carlstrom J, Kim S (2006) Quercetin-supplemented diets lower blood pressure and attenuate cardiac hypertrophy in rats with aortic constriction. $J$ Cardiovasc Pharmacol 47: 531-541.

27. Mink PJ, Scrafford CG, Barraj LM, Harnack L, Hong CP, et al. (2007) Flavonoid intake and cardiovascular disease mortality: a prospective study in postmenopausal women. Am J Clin Nutr 85: 895-909.

28. Eddouks M, Maghrani M, Lemhadri A, Ouahidi ML, Jouad H (2002) Ethnopharmacological survey of medicinal plants used for the treatment of diabetes mellitus, hypertension and cardiac diseases in the south-east region of Morocco (Tafilalet). J Ethnopharmacol 82: 97-103.

29. Engler MM, Engler MB, Pierson DM, Molteni LB, Molteni A (2003) Effects of docosahexaenoic acid on vascular pathology and reactivity in hypertension. Exp Biol Med (Maywood) 228: 299-307.

30. Aguila MB, Sa Silva SP, Pinheiro AR, Mandarim-de-Lacerda CA (2004) Effects of long-term intake of edible oils on hypertension and myocardial and aortic remodelling in spontaneously hypertensive rats. J Hypertens 22: 921-929.

31. Osicka TM, Russo LM, Qiu ML, Brammar GC, Thallas V, et al. (2003) Additive effects of hypertension and diabetes on renal cortical expression of PKC-alpha and -epsilon and alpha-tubulin but not PKC-beta 1 and -beta 2. J Hypertens 21: $2399-2407$.

32. Lermioglu F, Bagci S, Onderoglu S, Ortac R, Tugrul L (1997) Evaluation of the long-term effects of oleum origani on the toxicity induced by administration of streptozotocin in rats. J Pharm Pharmacol 49: 1157-1161.

33. Wang YL, Wang CY, Zhang BJ, Zhang ZZ (2009) Shenfu injection suppresses apoptosis by regulation of $\mathrm{Bcl}-2$ and caspase- 3 during hypoxia/reoxygenation in neonatal rat cardiomyocytes in vitro. Mol Biol Rep 36: 365-370.

34. Basu A, Sivaprasad U (2007) Protein kinase Cepsilon makes the life and death decision. Cell Signal 19: 1633-1642.

35. Choi H, Kim SH, Chun YS, Cho YS, Park JW, et al. (2006) In vivo hyperoxic preconditioning prevents myocardial infarction by expressing bcl-2. Exp Biol Med (Maywood) 231: 463-472.

36. Murphy E2004) Primary and secondary signaling pathways in early preconditioning that converge on the mitochondria to produce cardioprotection. Circ Res 94: 7-16.

37. Narula J, Pandey P, Arbustini E, Haider N, Narula N, et al. (1999) Apoptosis in heart failure: release of cytochrome $c$ from mitochondria and activation of caspase-3 in human cardiomyopathy. Proc Natl Acad Sci U S A 96: 8144-8149. 
Citation: Faruk EM, ElSawy NA, El desoky RE (2015) Histological, Immunohistochemical and Biochemical Study on the Possible Cardioprotective and Antihypertensive Role of the Flavonoid in Unilateral Renal Artery Ligation of Adult Albino Rats. J Cytol Histol 6: 326. doi:10.4172/21577099.1000326

Page 8 of 8

38. Narula J, Arbustini E, Chandrashekhar Y, Schwaiger M (2001) Apoptosis and the systolic dysfunction in congestive heart failure. Story of apoptosis interruptus and zombie myocytes. Cardiol Clin 19: 113-126.

39. Clerk A, Cole SM, Cullingford TE, Harrison JG, Jormakka M, et al. (2003) Regulation of cardiac myocyte cell death. Pharmacol Ther 97: 223-261.

40. Narula J, Kolodgie FD, Virmani R (2000) Apoptosis and cardiomyopathy. Curr Opin Cardiol 15: 183-188.

41. Fortuño MA, González A, Ravassa S, López B, Díez J (2003) Clinica implications of apoptosis in hypertensive heart disease. Am J Physiol Heart Circ Physiol 284: H1495-1506.

42. Communal C, Sumandea M, de Tombe P, Narula J, Solaro RJ, et al. (2002) Functional consequences of caspase activation in cardiac myocytes. Proc Nat Acad Sci U S A 99: 6252-6256.

43. Laugwitz KL, Moretti A, Weig HJ, Gillitzer A, Pinkernell K, et al. (2001) Blocking caspase-activated apoptosis improves contractility in failing myocardium. Hum Gene Ther 12: 2051-2063

44. Oskarsson HJ, Coppey L, Weiss RM, Li WG (2000) Antioxidants attenuate myocyte apoptosis in the remote non-infarcted myocardium following large myocardial infarction. Cardiovasc Res 45: 679-687.

45. Hawas UW, El-Desoky SK, Kawashty SA, Sharaf M (2008) Two new flavonoids from Origanum vulgare. Nat Prod Res 22: 1540-1543.

46. Spiridon I, ColceruS, AngheIN, Teaca CA, BodirlauR, et al. (2011) Antioxidant capacity and total phenolic contents of oregano (Origanum vulgare), lavender (Lavandula angustifolia) and lemon balm (Melissa officinalis) from Romania Natural Product Research: Formerly Natural Product Letters 25: 1657-1661.

47. Serbecic N, Beutelspacher SC (2005) Anti-oxidative vitamins prevent lipidperoxidation and apoptosis in corneal endothelial cells. Cell Tissue Res 320 465-475. 